\title{
SUBURBANIZACIÓN Y CAMBIO SOCIAL EN LA METRÓPOLI MADRILEÑA
}

SUBURBANISM AND SOCIAL CHANGE IN MADRID METROPOLIS

Fernando Díaz Orueta*

María Luisa Lourés Seoane**

\section{RESUMEN}

El artículo se centra en Madrid y su reciente desarrollo suburbano. El proceso de suburbanización se ha extendido más allá del Área Metropolitana, alcanzado buena parte de la región. El texto analiza la relación entre la suburbanización y las nuevas pautas de desigualdad socio-espacial. La segregación se ha visto reforzada no solo por los precios de la vivienda, sino también por las largas distancias y las oportunidades de movilidad.

PALABRAS CLAVE: SUBURBANIZACIÓN * CAMBIO SOCIAL * SEGREGACIÓN * ESPACIO * VIVIENDA

ABSTRACT

The article focuses on Madrid and its recent suburban development. The suburbs occupy not only most of the Madrid Metropolitan Area, but also a significant part of the Madrid Region. We analyze the relation between suburbanism and new patterns of socio-spatial inequality. Segregation has been reinforced not only by housing prices, but also by long distances and mobility chances.

KEYWORDS: SUBURBANISM * SOCIAL CHANGE * SEGREGATION * SPACE * HOUSING

Universidad de La Rioja, España.

fernando.diaz@unirioja.es

** Universidad de Zaragoza, España.

mlloures@unizar.es 


\section{INTRODUCCIÓN}

Desde los años 80 del siglo xx, la estructura socio-espacial de las ciudades españolas se ha modificado profundamente. El modelo espacial anterior, de carácter compacto, se ha visto reemplazado por uno nuevo de carácter extensivo, caracterizado por la preponderancia del uso del automóvil privado como forma primordial de desplazamiento, los nuevos desarrollos urbanos con fuertes impactos en lo que se refiere a la conformación de los espacios públicos y la creación de nuevas centralidades, básicamente grandes centros comerciales y de ocio. El pinchazo de la burbuja inmobiliaria ha reforzado las consecuencias sociales y ambientales más negativas del proceso de suburbanización.
El artículo se centra en la Comunidad de Madrid, región española en la que el proceso de suburbanización se ha expresado con gran rotundidad y en la que destaca también la rapidez de su despliegue ${ }^{1}$. De hecho, la estructura clásica centro/periferia ha quedado atrás y cada vez más autores utilizan el término "conurbación difusa" para referirse a la nueva realidad madrileña. Su estructura social y espacial ya no responde al esquema con el que fue descrita hasta los años 80: los nuevos suburbios, conformados a partir de viviendas unifamiliares $y / 0$ edificios multifamiliares, ocupan ya no solo una gran parte del Área Metropolitana de Madrid, sino también una porción significativa del resto de la región (Corona Provincial).

MAPA 1

COMUNIDAD DE MADRID (ESPAÑA)

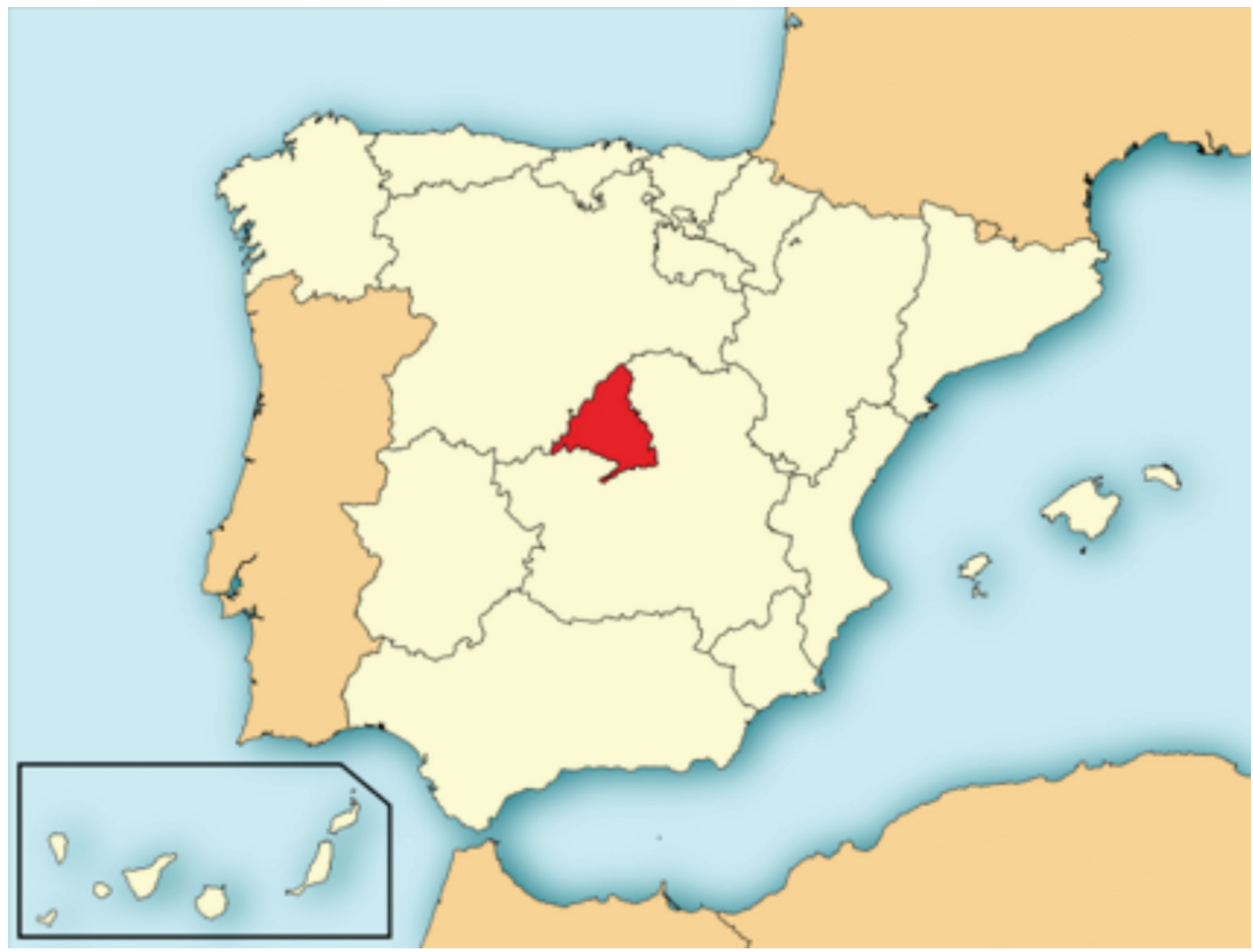

Fuente: http://es.wikipedia.org/wiki/Archivo:Localizaci\%C3\%B3n_de_la_Comunidad_de_Madrid.svg

$1 \quad$ Situada en el centro de la Península Ibérica (Mapa1), la región de Madrid (Comunidad de Madrid) ocupa una superficie de $8028 \mathrm{~km}^{2}$, constituida por 179 municipios. De acuerdo a los datos del Instituto Nacional de Estadística (INE), en
2009 su población ascendía a 6386932 habitantes, de los cuales 3255944 residían en la ciudad de Madrid (su capital), 2642191 en el Área Metropolitana y el resto, 488 797, en la Corona Provincial (Mapa 2). 


\author{
MAPA 2 \\ COMUNIDAD DE MADRID \\ (CIUDAD DE MADRID, ÁREA METROPOLITANA Y CORONA PROVINCIAL)
}

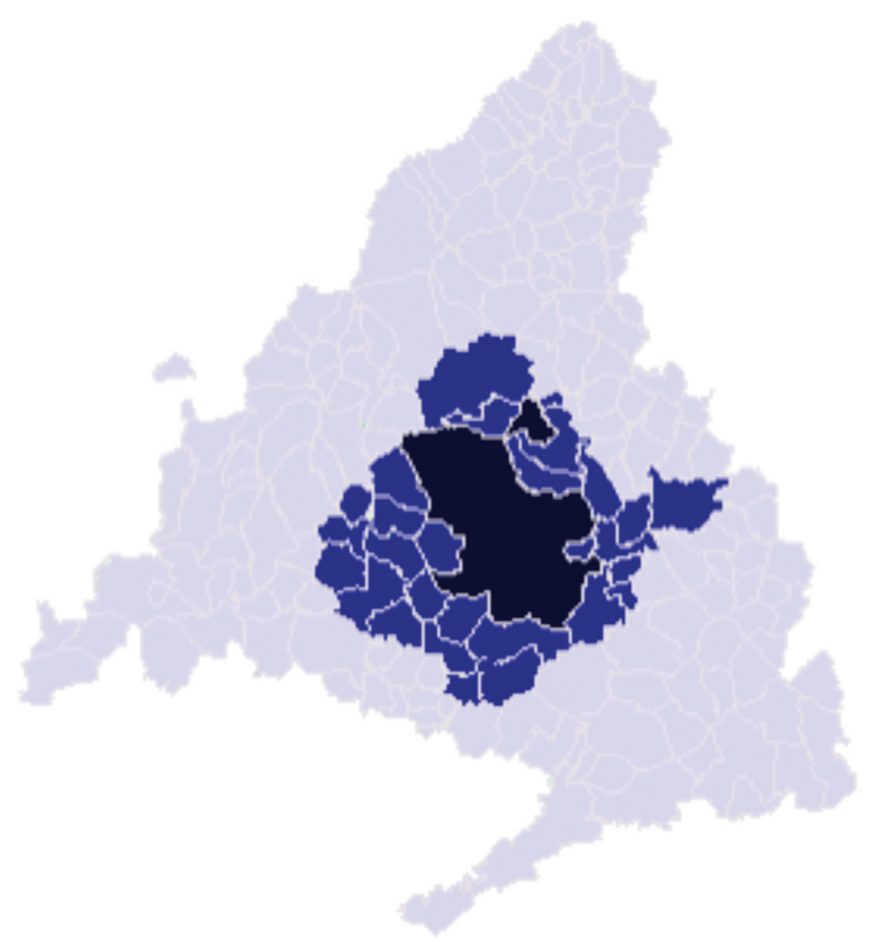

Fuente: Atlas Estadístico de la Comunidad de Madrid, 2005

Ahora bien, este proceso acelerado de cambio no ha respondido a un proyecto planificado que pretendiera dar respuesta a las demandas sociales de los habitantes de Madrid, sino al contrario, ha sido fundamentalmente la consecuencia de una política de crecimiento promovida por los gobiernos locales, regional y central, respaldada por los principales grupos empresariales de la región.

Partiendo de la constitución del suburbio proletario en la primera mitad del siglo Xx y su desarrollo posterior hasta los años 80, el artículo se centra en las dos últimas décadas, planteándose como objetivo el análisis de la relación entre la suburbanización, la composición social de los nuevos espacios residenciales y las nuevas pautas de desigualdad socio-espacial. Es preciso profundizar en el análisis de un espacio regional no solo más difuso desde el punto de vista espacial, sino también cada día más complejo en cuanto a su composición social y fuertemente jerarquizado. Comprender esta nueva realidad y su lógica de funcionamiento resulta trascendental para afrontar desde el territorio madrileño, el colapso de un modelo económico agotado y repensar el futuro.

\section{ANTECEDENTES: EL SUBURBIO PROLETARIO DE MADRID}

La miseria es tan enorme, que difícilmente se puede explicar. Sin muebles, sin vestidos, sin casi comida, así viven muchos miles de almas en las afueras 
de Madrid; dedicados a la busca, a la ratería y a la mendicidad, depauperados $y$ recelosos. Masa en la que se ceba la tuberculosis y que espera siempre la convulsión social o política que le permita dar satisfacción a sus anhelos de disfrute de tantas y tantas maravillas como la ciudad ofrece a su envidia impotente. (...) Más allá de Tetúan surgen nuevos barrios... suburbios del suburbio, y en ellos aparecen ya fenómenos de virulencia roja, rencor latente e inmoralidad agudizada (Patronato de Protección a la Mujer, Informe sobre la moralidad pública, 1943/44) $)^{2}$.

A principios de los años 40 del siglo XX, Madrid, la ciudad recién aplastada por el fascismo, vivía una situación social extrema. La miseria $y$ el hambre se manifestaban con una crudeza si cabe, más aguda en sus extrarradios, un territorio observado con gran desconfianza por el nuevo régimen puesto que fundamentalmente, allí se concentraba la población proletaria. No debe olvidarse que la Guerra Civil Española fue, por encima de todo, una guerra de clases.

Como señaló Prieto Moreno $(1948)^{3}$, entre 1900 y 1940, Madrid había duplicado su población hasta superar el millón de habitantes y lo había hecho sin ningún plan de ordenación, excepto el desarrollo del ensanche central. Alrededor de la ciudad se concentraban 300000 personas en condiciones de pobreza extrema. Con la progresiva anexión de municipios de su Corona Metropolitana, a principios de los años 50 podía hablarse del Gran Madrid, una aglomeración urbana en la que en 1955 habitaban 1724674 personas (Díaz, 2001: 226).

El nuevo régimen totalitario, de cariz marcadamente centralista y receloso de la fortaleza económica y de las ansias de autonomía del País Vasco y Cataluña, se propuso reforzar Madrid no solo como capital política, sino también como principal polo de actividad económica del país. A lo largo de los años 50, el

2 Texto citado por Gavira (1999: 130). crecimiento de Madrid se intensificó con la llegada de inmigrantes procedentes de distintas regiones españolas (las dos Castillas, Andalucía, Extremadura, etc.) y los peores años de la posguerra fueron quedando atrás; sin embargo, la infravivienda, el hacinamiento, la carencia de servicios y los equipamientos ${ }^{4}$ eran la pauta más común en los barrios populares, concentrados fundamentalmente al sur de una ciudad que en 1960 sumaba ya más de dos millones de habitantes ${ }^{5}$. Su estructura socio-espacial continuó polarizándose dando forma a un eje espacial de desigualdades que con matices, se mantendría en las décadas posteriores (Díaz, 2001).

A finales de los años 50, las autoridades franquistas percibieron que su pretensión de perpetuarse en el poder político pasaba, además de por su alianza con los EeuU y el Vaticano, por la puesta en práctica de una serie de medidas de liberalización de la economía. Los años 60 y el inicio de los 70 pueden caracterizarse en España como la etapa de consumación de la industrialización capitalista (Ortí, 1990). La economía madrileña se reforzó notablemente y la población de la ciudad creció rápidamente pasando de 2177 123 habitantes en 1960 a 3120941 en 1970.

El Plan General de Madrid de 1963, se planteó entre sus objetivos el dar una respuesta a los graves problemas de la ciudad y su Corona Metropolitana, pero los resultados fueron escasos. Como plantean Leira et ál. (1976), el Plan optó por una visión socio-espacialmente segregada: se reservó un crecimiento extensivo suburbano de baja densidad y con una mayor calidad ambiental para el Oeste y Noroeste, mientras que para el Este $y$ con toda claridad para el Sur, se optaba por un crecimiento residencial intensivo, acompañado en muchos casos de la presencia de actividades industriales

4 Abastecimiento de agua en camiones cisterna, ausencia de alcantarillado, deficiente recogida de basuras, transporte colectivo en camionetas (cuando las había), etc. (Leira et ál., 1976).

5 Como señala Capel (1983), ante la urgencia de la situación, la dictadura favoreció la construcción de polígonos de vivienda barata en la periferia, destinados a la clase obrera. La mayoría de ellos estaban mal comunicados con la ciudad consolidada, presentando graves carencias en equipamientos e infraestructuras. 
contaminantes. Incluso se utilizaba abiertamente el término "ciudades-dormitorio" para referirse a los municipios del Sur.

Al calor del Plan Nacional de la Vivienda de 1961, se disparó la construcción de nuevas viviendas de promoción privada y en menor medida pública, en general, de una calidad pési$\mathrm{ma}^{6}$, a la vez que comenzaba la ocupación de áreas cada vez más alejadas del centro de la ciudad. La especulación se desbocó, aprovechándose hasta el último resquicio para conseguir el mayor lucro económico, recalificando terrenos $y$ creando espacios urbanos con grandes carencias, desarticulados y deficientemente comunicados con el centro de la metrópoli, aunque dependientes de él en muchos aspectos. Ligadas a la dictadura, surgieron entonces muchas de las grandes empresas inmobiliario-constructivas españolas que todavía hoy se mantienen (Naredo, 2011: 29).

Dado que buena parte de la actividad económica se concentraba en el corazón metropolitano, los movimientos pendulares desde la periferia se hicieron más intensos. En estos años, la mayor parte de la inversión estatal en el campo de la movilidad se centró en el fomento del uso del automóvil: se suprimieron bulevares, se construyeron pasos elevados, se crearon aparcamientos y a la vez, se mejoraron las vías de acceso a Madrid (Fernández, 1981: 6).

Es decir, el Estado a través de las inversiones en el sistema de transportes especialmente ( $y$ junto con las realizadas en infraestructuras básicas y en vivienda), ha potenciado $y$ ha hecho factible el modelo territorial más acorde con los intereses del capital en esta fase, $y$ a su vez ha primado aquellos medios de transporte más ligados a las industrias punta (sector del automóvil) y, en general, los medios de transporte motorizado, que requieren importantes inversiones y que

$6 \quad$ En 1974, se estimaba que 587000 familias (el $58,9 \%$ del total de las residentes en la ciudad de Madrid y su Corona Metropolitana), habitaban en viviendas inadecuadas. Es decir, en chabolas o en viviendas en situación de ruina, carencia de servicios, tamaño insuficiente, etc. (Díaz, 2001: 231-232) implican elevados costos de explotación, marginando aquellos medios de transporte no motorizados (peatonal, bicicleta,...) de carácter autónomo, que requieren poca inversión, ya que perjudicaban los mecanismos de concentración y acumulación de capital (Fernández, 1981: 6).

En los años finales de la dictadura, el suburbio madrileño, abandonado a su suerte durante tanto tiempo, se convirtió en el principal foco de conflictividad social y política contra el franquismo. Como afirma Gavira (1999: 144), la capacidad de organización de sus habitantes y lo urgente de sus reivindicaciones, dio lugar a la emergencia de unos movimientos urbanos que resultarían trascendentales en la historia de la ciudad.

\section{CIUDAD Y DEMOCRACIA: EL CAMBIO HACIA UN NUEVO MODELO TERRITORIAL}

En 1979, tras la celebración de las primeras elecciones democráticas en más de cuarenta años, la agenda urbana de los nuevos ayuntamientos se centró, fundamentalmente, en saldar la deuda histórica acumulada durante la dictadura, dando una respuesta urgente a las demandas de los movimientos urbanos. De hecho, la primera mitad de los años 80 fue un periodo de transformación muy importante en las ciudades españolas. La inversión en vivienda, la construcción de nuevos equipamientos, la mejora de la red de transporte colectivo, la creación de infraestructuras básicas, etc., modificaron notablemente su realidad social y urbanística. Todo ello fue realizado en un contexto de crisis económica.

En la mayor parte de los barrios periféricos de la ciudad y de los municipios del Área Metropolitana, se produjo una transformación histórica que se materializó sobre todo en notables cambios espaciales. Desde el punto de vista social, la situación evolucionó de manera diferente $y$ a pesar de las mejoras, los mayores índices de pobreza y exclusión continuarían (y continúan ${ }^{7}$ ) concentrándose

$7 \quad$ Aunque, desde luego, menores a los registrados en décadas pasadas. 
en las mismas áreas de la ciudad y su Corona Metropolitana.

En cuanto a la evolución demográfica, desde la segunda mitad de los 70, el crecimiento de la ciudad de Madrid se había estancado. Los movimientos migratorios se frenaron en seco, entre otras razones por la crisis económica que afectó de forma especial al sector industrial. De hecho, entre 1975 y 1981, la ciudad de Madrid perdió población en números absolutos, fenómeno que se repetiría entre 1981 y 1986. En paralelo, los movimientos migratorios intrametropolitanos emergieron cada vez con más intensidad ${ }^{8}$, se trataba sobre todo del desplazamiento de nuevas familias que desde el interior de la ciudad se trasladaban a vivir a municipios de la periferia Sur y Este, donde los precios de la vivienda eran más asequibles. A partir del periodo 1981-1986, comenzaron a ser también muy notables las migraciones hacia las áreas Norte y Oeste, en este caso protagonizadas por grupos sociales con mayores ingresos que se desplazaban hacia los espacios más descongestionados y de mayor calidad ambiental del Área Metropolitana.

Entre 1986 y 1991, una etapa de claro crecimiento económico, la tendencia al crecimiento de las áreas más periféricas se mantendría, alcanzando con toda claridad a la Corona Provincial ${ }^{9}$ :

(...) durante la etapa de recuperación económica (1986-1991) se ha confirmado la tendencia a que los mayores ritmos de crecimiento poblacional se vayan desplazando hacia zonas exteriores del Área Metropolitana y a ciertas zonas de la Corona Provincial. En este último espacio, el proceso alcanza una intensidad desconocida con anterioridad, siendo ya cuatro las zonas que experimentan crecimientos

$8 \quad$ Al respecto: Méndez, 1994.

$9 \quad$ Es decir, se superaban los límites del Área Metropolitana, para "conquistar" el resto del territorio de la Comunidad de Madrid. Con los años, este crecimiento superaría también los límites administrativos de la región, internándose con claridad en las provincias limítrofes de Guadalajara y Toledo (Comunidad Autónoma de Castilla-La Mancha). superiores al 20\%. (...) Es posible preveer que se estén extendiendo por la Corona Provincial las pautas de ubicación socioespacial de la población detectadas en el Área Metropolitana. Es decir, hacia el Oeste y Noroeste se dirigirá la población de mayores recursos $y$ hacia el Sur y el Este las personas de un poder adquisitivo menor (Díaz, 1992: 504).

En consecuencia, la Comunidad de Madrid tomaba cada vez más la forma de una Región Metropolitana ${ }^{10}$. Los grandes flujos migratorios de los años 60 y al inicio de los 70 , se detuvieron y la región alcanzó casi el equilibrio entre inmigración y emigración. Sin embargo, los movimientos dentro de la región, sobre todo desde la ciudad central al Área Metropolitana y cada vez más a la Corona Provincial, producían una ocupación creciente del suelo regional, acentuada por el gran volumen de la vivienda de segunda residencia ${ }^{11}$.

En esa Región Metropolitana en construcción, el peso de la capital seguía siendo notable, aunque progresivamente se avanzaba hacia un territorio multicéntrico. La recualificación urbanística del antiguo suburbio proletario, unida a la puesta en práctica de políticas locales dirigidas a dotar de mayor actividad y atractivo a los antiguos barrios y ciudades dormitorio, ayuda a explicar esta transformación. En líneas generales, no se está ante la constitución del suburbio anglosajón "clásico", aunque, desde luego, existan áreas de baja densidad y vivienda unifamiliar ${ }^{12}$.

$10 \quad$ En 1991, habitaban la Comunidad de Madrid 4845 851 personas, de las cuales 2909792 lo hacían en la capital, 1579875 en la Corona Metropolitana y 356184 en la Corona Provincial.

11 Sobre la Sierra Norte de Madrid: Lourés Seoane, 2002 .

12 A lo largo de los años ochenta las promociones de vivienda unifamiliar, fundamentalmente adosa$\mathrm{da}$, se extendieron por los municipios del Oeste y Noroeste de la Corona Metropolitana dirigidas a sectores de clase media-alta. Poco después, esta tipología residencial se puso también en práctica al Sur y al Este, destinada esta vez a sectores de clase media y ciertos grupos de clase trabajadora. Con los ingresos obtenidos por la venta 
La situación tampoco era comparable a la de la extensión del suburbio proletario de décadas anteriores, puesto que ahora los protagonistas de este nuevo proceso, incluso en las áreas del Sur y Este, se desplazaban a residir a áreas con mayores equipamientos y servicios ${ }^{13}$, y su situación socio-económica era muy diferente.

Eso sí, muchas de las personas que emigraron desde la ciudad central hacia las nuevas áreas urbanas de las periferias Sur y Este, lo hicieron acuciados por el crecimiento imparable de los precios de la vivienda, generado por el boom inmobiliario de la segunda mitad de los años 80 (Leal, 1987). Un boom inmobiliario estrechamente relacionado con la entrada de España en la Unión Europea el 1 de enero de 1986.

\section{LA CONURBACIÓN DIFUSA MADRILEÑNA ${ }^{14}$}

A mediados de los años 90, el cambio desde una agenda urbana que en los primeros tiempos de democracia local había estado marcada por el derecho a la ciudad y la justicia

de la vivienda anterior y gracias a las facilidades de endeudamiento masivo, estos grupos sociales accedían a una nueva vivienda. Como señaló Leal (1994: 77), el Sector 3 de Getafe (periferia Sur) representó muy bien estos últimos movimientos: los nuevos moradores del barrio eran familias que buscaban mejorar sus condiciones de vida sin alejarse en exceso de sus barrios de origen y nuevas familias que querían mantener la cercanía con el medio social de procedencia.

13 Lo que no quiere decir que no hubiera problemas importantes, de manera especial estaba el del transporte. Por ejemplo, en el otoño-invierno de 1989-1990, se produjeron importantes movilizaciones sociales (bloqueo de vías, manifestaciones, destrucción de instalaciones, etc.) en distintas estaciones del ferrocarril de cercanías motivadas, en la mayor parte de los casos, por la saturación y la imposibilidad de llegar a tiempo al puesto de trabajo (Díaz, 2001: 476-480).

14 Distintos autores, entre ellos Naredo (2010), utilizan este término para referirse al territorio-red metropolitano, tejido en torno a los principales ejes de un viario cada vez más denso y transitado. El crecimiento de la conurbación ha llegado a descontrolarse, desvinculándose por completo de la evolución demográfica para responder solo a la coyuntura económica. En su expansión destruye los sistemas agrarios y engulle los asentamientos urbanos pre-existentes. social, a otra plenamente alineada con los fundamentos básicos de lo que ha sido calificado como Urbanismo Neoliberal (Brenner y Theodore, 2002), se había consumado plenamente ${ }^{15}$. Desde mediados de la década de los 80 , se había ido consolidando un pacto tácito que trataba de convertir a Madrid en el área urbana española mejor situada en el nuevo escenario económico mundial (Díaz, 1994). En ese acuerdo participaban las distintas administraciones (local, regional $y$ central) $y$ diferentes grupos sociales $y$ económicos de la región, en especial el empresariado y el capital financiero. Como adelantara tempranamente Ortí (1990), Madrid reforzaba todavía más su papel preponderante en el sistema económico y territorial español.

El gobierno autonómico, constituido en 1983, jugó un papel esencial como impulsor de distintas actuaciones orientadas a convertir la región en un espacio metropolitano competitivo, en el contexto urbano europeo. Desde el ámbito municipal, la apuesta también fue clara. Así, en 1993, el Avance del Plan General de Madrid $^{16}$ afirmaba:

(...) Madrid puede tener claras opciones de especialización internacional en los flujos de América y África hacia Europa $-y$ viceversa- al tiempo que complemente las necesidades de servicios y la competitividad del arco mediterráneo, vinculándose activamente al mismo.

Desde el sector público se crearon agencias orientadas a impulsar los procesos de globalización, favoreciendo los intereses de los sectores empresariales:

15 Roch (2006: 52) sitúa en 1985 el momento en el que se inició el cambio de modelo en Madrid: “(...) una sobreproducción de espacio social - socialmente diferenciado $y$ excluyente como veremos$y$ de servicios - con sus sistemas generales-, territorialmente extensiva y económicamente sobrevalorada, en torno a la cual se genera un poderoso mecanismo de acumulación del que se benefician especialmente las empresas implicadas en su construcción, lo que les permite apenas veinte años después dar el salto al espacio global, en posiciones muy ventajosas". 
En el caso de Madrid, destaca el caso de Arpegio e Imade que actúan mediante: la creación de grandes operaciones de suelo urbanizado para Parques Tecnológicos, Grandes Áreas de Terciario, Ciudades Aeroportuarias, Ciudades de la Imagen..., con el fin de reducir los costes de localización para las grandes empresas, principalmente transnacionales (...); y la cooperación e internacionalización empresarial, promoviendo la imagen de Madrid en los mercados mundiales con el fin de atraer inversiones (Fernández y Vega, 1994: 301).

Por lo tanto, en ese momento los nuevos discursos urbanos estaban totalmente asentados. La orientación hacia el crecimiento económico y la competencia entre ciudades como objetivos centrales, acompañados de la defensa de las privatizaciones, la desregulación, la flexibilidad en la gestión y las nuevas fórmulas de colaboración público-privado pasaron a formar parte del vocabulario cotidiano de políticos $y$ gestores. La nueva apuesta económica tuvo consecuencias inmediatas $y$ trascendentales en el territorio madrileño, que en un breve periodo de tiempo, se vio radicalmente modificado, avanzando hacia el modelo de "conurbación difusa".

Como señala Roch, el crecimiento de la Comunidad de Madrid desde mediados de los años 90 tuvo en la producción inmobiliaria, especialmente de viviendas, uno de sus principales ejes, dando lugar a un auténtico desbordamiento:

(...) como espectacular ha sido y sigue siendo la evolución al alza del conjunto de precios de los alojamientos, o la extensión incontrolable sobre el territorio regional de su física metropolitana, por no hablar del incremento constante de su parque de viviendas vacías, del desarrollo imparable de sus infraestructuras de transporte, del volumen de la hipoteca que aplasta a la ciudad $y$ a sus ciudadanos, y que ya se extiende hasta mediados del siglo como una oscura nube (...) (2006: 50).
Es decir, en Madrid, como en otras áreas urbanas españolas, la alianza financiero-inmobiliaria disfruta de una posición hegemónica. La capacidad de acumulación del sector, cada vez más internacionalizado, ha sido enorme y la implicación de los responsables políticos, creando las condiciones que lo han permitido, ha sido total. En esta nueva etapa histórica, la producción del espacio se convirtió en actividad central, generando un divorcio entre las necesidades de la población y el papel creciente que asume el espacio como acumulador estable de riqueza y trampolín para que las empresas que lo producen salten al mundo global. Así, como plantea Roch (2006), Madrid pasó a ser, fundamentalmente, espacio inmobiliario, un espacio social de exclusión organizado para acumular la renta de sus residentes de acuerdo a una rígida estructura jerárquica que sitúa a cada uno "en su lugar".

Para que esto fuera posible, el poder político favoreció el proceso, acompañándolo con unos cambios legislativos ad hoc que allanaron el terreno, abriendo paso a auténticos "neocaciques" locales y regionales, forzando un ritmo de construcción nueva que hizo de España el primer productor de viviendas y consumo de cemento (Naredo, 2011: 14-15).

En la Comunidad de Madrid, este proceso se tradujo en una ocupación masiva del suelo regional. De acuerdo a los datos del Observatorio Metropolitano (2007: 227-238), entre 1993 y 2003, la región experimentó un crecimiento poblacional del $12 \%$, mientras el suelo ocupado crecía un $47 \%$. Es decir, en diez años el suelo urbano aumentaba prácticamente la mitad de lo que lo había hecho en toda su historia y lo hacía en un contexto de crecimiento demográfico moderado ${ }^{17}$. La confluencia de la liberalización del mercado del suelo, la utilización de la producción de suelo como una fuente de financiación municipal, el interés de los propietarios de suelo en urbanizar sus terrenos y la demanda creciente de viviendas, favorecieron un proceso que solo se vio frenado con la irrupción de

17 De hecho, la urbanización es uno de los factores que más está contribuyendo en España a la desertificación (Ecologistas en Acción, 2007: 18-21). 
la crisis en $2007^{18}$. El crecimiento no mantenía una relación con las necesidades de vivienda del conjunto de la población:

Nos encontramos así ante una situación de crecimiento demográfico suave, con uno de los mayores índices de viviendas por habitante, con una alta concentración de viviendas en manos de las clases más altas (compradas como inversión), pero también con una población con necesidades de alojamiento insatisfechas, en la misma medida en que sigue sin poder acceder a una vivienda. Y esto cuando paradójicamente existen suficientes viviendas para alojar a todo el mundo (Observatorio Metropolitano, 2007: 235).

El crecimiento de esta conurbación difusa habría resultado imposible sin la extensión de la red viaria de carreteras (López de Lucio, 1995). Madrid es hoy la región urbana europea con más kilómetros de autopista (con y sin peaje) en relación a su población (El Ecologista, 2009: 9). Entre 1985 y 2009, los kilómetros de vías de gran capacidad ${ }^{19}$ pasaron de 218 a 970 . En 2009, la región con una superficie de 8028 $\mathrm{km}^{2}$ y una población de 6386932 habitantes, contaba con una red de carreteras de 3341 kilómetros ${ }^{20}$.

La inversión ha sido también mayúscula en la red de ferrocarriles de alta velocidad (AVE) $y$ en el Aeropuerto de Barajas, concentrando una parte muy significativa de las inversiones realizadas en el conjunto del territorio español. La política de construcción y ampliación de grandes infraestructuras de transporte ha sido un pilar fundamental de la estrategia para reforzar a Madrid como eje central de la economía española (Segura, 2011).

TABLA 1

DISTRIBUCIÓN ESPACIAL DE LA POBLACIÓN, LA VIVIENDA Y LA SUPERFICIE OCUPADA (RESIDENCIAL Y OTROS)

\begin{tabular}{|c|c|c|c|c|c|c|c|c|c|c|c|c|}
\hline & \multicolumn{12}{|c|}{ COMPOSICIÓN PORCENTUAL (\%) DE LAS VARIABLES SELECCIONADAS } \\
\hline & \multicolumn{4}{|c|}{1956} & \multicolumn{4}{|c|}{1980} & \multicolumn{4}{|c|}{2005} \\
\hline & \multirow[b]{2}{*}{ Pobl. } & \multirow[b]{2}{*}{ Viv. } & \multicolumn{2}{|c|}{ Sup. ocupada } & \multirow[b]{2}{*}{ Pob. } & \multicolumn{3}{|c|}{ Sup. ocupada } & \multirow[b]{2}{*}{ Pob. } & \multirow[b]{2}{*}{ Viv. } & \multicolumn{2}{|c|}{ Sup. ocupada } \\
\hline & & & Resid. & Otros & & Viv. & & Otros & & & Resid. & Otros \\
\hline Madrid (municipio) & 87,3 & 85,6 & 57,4 & 56,7 & 67,4 & 64,0 & 25,3 & 30,4 & 52,9 & 53,6 & 20,0 & 25,8 \\
\hline Corona Metrop. & 5,7 & 6,6 & 16,8 & 19,9 & 28,4 & 27,8 & 35,0 & 42,1 & 39,7 & 35,0 & 40,6 & 49,3 \\
\hline Resto del territorio & 7,0 & 7,8 & 25,8 & 23,4 & 4,2 & 8,2 & 39,7 & 27,5 & 7,4 & 11,4 & 39,4 & 24,9 \\
\hline Total Com. Madrid & 100 & 100 & 100 & 100 & 100 & 100 & 100 & 100 & 100 & 100 & 100 & 100 \\
\hline
\end{tabular}

Fuente: Naredo, 2006: 20.

18 A finales de 2009, habría en la Región de Madrid 47637 viviendas nuevas sin vender, según datos de la Asociación de Promotores Madrileños (Asprima). Aproximadamente, un tercio de ellas se concentraban en la zona Sur (El Mundo, Suplemento Su Vivienda, 22 de enero de 2010).
19 Esta categoría incluye autopistas de peaje, autovías $y$ autopistas libre de peaje y vías de doble calzada.

20 Anuario Estadístico de la Comunidad de Madrid: $<$ http://www.madrid.org/iestadis/fijas/estructu/ general/ anuario/ianucap09.htm> 
La información de la Tabla 1, confirma que el peso demográfico de la ciudad de Madrid en el conjunto de la región no ha dejado de decrecer desde 1956: si en 1956 representaba el $87,3 \%$ del total de la población regional, en 2005 ese porcentaje era del 52,9\%. Al realizar el cálculo sobre el número de viviendas, los resultados son similares.

Entre 1956 y 1980, la Corona Metropolitana experimentó un importante incremento demográfico, pasando de representar el 5,7\% al 28,4\%, crecimiento que en el siguiente periodo continuaría hasta alcanzar el 39,7\% de la población. El aumento de la Corona Provincial (denominada "Resto del Territorio" en la investigación de Naredo) es más fuerte entre 1980 y 2005, pasando de representar el 4,2\% del total de la población de la región al 7,4\%. Desde mediados de los años 90 , todas las áreas experimentan crecimientos de población. Las variaciones en los porcentajes que representan sobre el total de la población se deben a la intensidad del crecimiento en cada zona ${ }^{21}$.

En cuanto a la ocupación del suelo, resulta destacable el importante peso con el que contaban tanto la Corona Metropolitana como la Provincial en 1956. Como señala Naredo (2006), esto se debe al desarrollo de la segunda residencia y a la existencia de un hábitat menos concentrado que en la capital. En varias zonas de la montaña también era importante el espacio ocupado por los embalses. En 1980, el gran crecimiento de la Corona Metropolitana se percibe con claridad en los datos sobre superficie ocupada.

\section{UN ESPACIO SOCIAL Y ESPACIALMENTE COMPLEJO}

Como se decía anteriormente, la suburbanización en la Región de Madrid ha ido acompañada de una redefinición del modelo inmobiliario. El precio de la vivienda aumentó

21 Incluso el municipio de Madrid ha recuperado población, pasando de 2957058 habitantes en 2001 a 3255944 en 2009 (Anuario Estadístico de la Comunidad de Madrid. En: <http://www. madrid.org/iestadis/fijas/estructu/general/anuario/ ianucap02.htm>). de forma continua, a la vez que crecía el número de viviendas disponibles:

Sólo en la metrópoli madrileña donde existen más de 300000 viviendas vacías $y$ otras 275000 claramente infrautilizadas, se vienen superando las 40000 nuevas viviendas en los últimos años y hay una disponibilidad de suelo ya clasificado para otras 800000 viviendas, que permitirían alojar holgadamente a Valencia y Sevilla juntas (Roch, 2004: 32).

El "nuevo" Madrid, el que va consolidándose sobre todo desde la segunda mitad de los 90 , no es solo mucho más extenso en superficie y degradado ambientalmente. Además, es un espacio social más jerarquizado. Son varias las investigaciones (Díaz, 2001; Observatorio Metropolitano, 2007 y Leal, 2007) que confirman la consolidación de un espacio social estructurado a partir de áreas con una composición socio-económica crecientemente homogénea. Asimismo, algunos estudios comparativos destacan que la tendencia a la segregación es mayor en Madrid que en otras ciudades europeas. Así lo afirma, por ejemplo, Preteceille (2000), en línea con las argumentaciones de Leal (2007: 34), enfatizando el papel jugado por la debilidad de las políticas de vivienda social en España.

Desde luego, la transformación del modelo inmobiliario es incomprensible si no se contextualiza en el marco del proceso de reestructuración experimentado por la economía madrileña. El crecimiento económico no hubiera resultado posible sin la incorporación de un flujo muy numeroso de trabajadores extranjeros. Durante los años 90 y en la primera década del siglo XXI, hasta la irrupción de la crisis, su crecimiento es sin duda, el rasgo más novedoso de la población madrileña. En enero de 2011, la población extranjera ascendía a 1103470 personas o, lo que es lo mismo, el 16,81\% del total de sus habitantes ${ }^{22}$ (Consejería de Empleo,

$22 \quad$ El grueso del crecimiento de la población de la Región de Madrid en las dos últimas décadas, se explica por este flujo migratorio, no equiparable en número al de los años 60 , pero muy significativo. 
Mujer e Inmigración, 2011). Una población que se distribuye por toda la región y que alcanza sus cotas más importantes de concentración porcentual (no así en valores absolutos) en varios municipios de la Corona Provincial ${ }^{23}$.

La tendencia principal en cuanto a su localización es a residir en áreas donde habita población local de características socioeconómicas parecidas. Así, por ejemplo, en la ciudad de Madrid comparten muchos barrios cuya composición mayoritaria es de clase trabajadora. Varios distritos del Sur (Carabanchel, Usera, Puente de Vallecas o Villaverde) presentan porcentajes superiores al $15 \%$, aunque los distritos con los porcentajes mayores son Centro y Tetúan, espacios centrales de tradición popular ${ }^{24}$ (Observatorio de las migraciones $y$ de la convivencia intercultural de la ciudad de Madrid, 2005) y con una presencia relativamente mayor de una oferta de vivienda en alquiler. De hecho, como recuerdan distintos autores (Leal, 2007 y Colectivo Ioé, 2007), las estrategias de primera residencia de los inmigrantes están muy marcadas por la posibilidad de acceder a una vivienda en alquiler antes de poder consolidar su preponderancia en España:

El hecho de que el $75 \%$ de los hogares compuestos por extranjeros estuviera en régimen de alquiler en el año 2003 frente al $13 \%$ de los españoles y que el centro tenga una proporción de alquileres que supera en más del doble al municipio de Madrid refleja un comportamiento residencial muy diferenciado que tiene fuertes consecuencias sobre el lugar y la forma de asentamiento de los inmigrantes.

Pero una vez que se saturó el centro y los precios de alquileres empezaron a elevarse la estrategia cambió de signo, podrían seguir encontrándose viviendas en lugares

23 El ejemplo más extremo es Fresnedillas de la Oliva, un pueblo de la Sierra Oeste de Madrid de 1600 habitantes en el que en enero de 2011, el $40,7 \%$ de la población era extranjera.

24 Sobre el barrio de Lavapiés en el distrito centro de Madrid: Lourés Seoane, 2003. centrales en alquiler, aunque a precios más elevados, lo que implicaba el recurso de hacinar dichas viviendas para poder pagar los alquileres exigidos, o alternativamente buscar en la extrema periferia, en lugares de segundas residencias o en zonas alejadas en las que los alquileres fueran menores (Leal, 2007: 42-43).

En los barrios obreros tradicionales, tanto de la ciudad de Madrid como del Área Metropolitana (sobre todo al Sur y Este), la afluencia de inmigrantes ha sido un factor fundamental que ha permitido a los habitantes locales alquilar o vender sus viviendas para acceder a otras de mayor calidad. Como afirma Roch (2004: 51), gracias a los inmigrantes, una parte del patrimonio inmobiliario que permanecía inmovilizado y que parecía haber perdido su valor, se reintrodujo en la dinámica inmobiliaria.

Pero además de los precios de la vivienda, otros factores contribuyen al afianzamiento de la segregación. Las oportunidades de trabajo, la red de transporte colectivo, la existencia y la calidad de los equipamientos educativos, sanitarios y otros, la oferta de servicios de consumo, la calidad del espacio público o la calidad medioambiental, entre otros, son factores importantes que se han visto muy afectados por el modelo de conurbación difusa. Muchas de las nuevas urbanizaciones construidas en los últimos veinte años han optado por diseños muy cerrados hacia el exterior, en no pocas ocasiones con protección de seguridad privada. Estas tipologías han ahondado la pérdida de espacios públicos puesto que, además, los grandes centros comerciales y de ocio han ido sustituyendo al pequeño comercio tradicional. Así ocurre no solo en algunos de los PAUs desarrollados en Madrid a partir del Plan de 1997 (por ejemplo, Sanchinarro, Las Tablas, Montecarmelo), sino también en los desarrollos medios o grandes de los municipios exteriores a la ciudad central.

Concretamente es en los grandes desarrollos inmobiliarios más recientes, construidos en plena euforia neoliberal, donde los problemas se acumulan con mayor intensidad. Algunos de los ejemplos más extremos se sitúan fuera de los límites administrativos de la 
región, en áreas contiguas de regiones vecinas claramente alcanzadas por la conurbación difusa madrileña. Una de las macro-operaciones especulativas más reseñables de esta etapa es "Ciudad Valdeluz" (Véase: <http://www.ciudadvaldeluz.com/>), un megaproyecto inmobiliario construido sobre suelo rústico recalificado (Prada, 2010) y junto a una nueva estación del AVE Madrid-Barcelona ${ }^{25}$. Si se hubieran cumplido las previsiones iniciales este núcleo alcanzaría más de 30000 habitantes, pero la crisis económica se interpuso en el proyecto, dejando por el momento un paisaje urbano de abandono, obras inacabadas $y$ déficit urbanísticos. A principios de 2011, el diario El País publicaba un reportaje donde se hablaba de Ciudad Valdeluz a través de la vida de dos de sus habitantes:

La perspectiva aérea de Valdeluz hace torcer el gesto. (...) Se ven cuadrículas de asfalto y solares vacíos, como si fuera un bloc de notas en blanco. Solo hay vida en una esquina, sin nada alrededor, más que carreteras, caminos, tierras de labranza, un vértice que habitan Paula y Pavel y otras 1.200 personas. (...) (Valdeluz) lo tenía todo a favor: una estación de AVE, la proximidad con Madrid, los precios competitivos. Pensada para crecer decía un video promocional (Abril 2011: 32-33).

Algo no muy distinto a lo que sucede al Sur, en comarcas como La Sagra, en la provincia de Toledo (también perteneciente a la Comunidad de Castilla-La Mancha), fronteriza con Madrid. En dicha comarca, a $35 \mathrm{~km}$ de la capital española, se encuentra una de las más grandes concentraciones de pisos $y$ chalés en venta del país ${ }^{26}$. En municipios como Seseña se yerguen grandes proyectos residenciales inacabados, mal equipados, obviamente desproporcionados, en los que sus habitantes, atraídos en su día por unos

25 A unos $65 \mathrm{~km}$ al Noreste de Madrid y a unos $8 \mathrm{~km}$ de la ciudad de Guadalajara, dentro del término municipal del pequeño municipio rural de Yebes.

Véase: <http://www.elmundo.es/elmundo/2011/04/14/suvivienda/1302800550.html> precios más asequibles, deben afrontar ahora un sinfín de problemas cotidianos.

En definitiva, a pesar de las notables transformaciones ocurridas en estos años, la tendencia global a la existencia de un eje de diferenciación socio-espacial Noroeste-Sur, que ya era identificado años atrás (Leal, 1994 y Díaz, 2001), se mantiene en lo esencial. Es cierto que con una composición social más compleja, sobre todo por el asentamiento de la población inmigrante y por los procesos de movilidad social de los autóctonos. También extendiéndose, con mayor o menor rotundidad, no solo a la Corona Provincial, sino también a otros territorios de provincias colindantes.

\section{AFRONTAR LA CRISIS DESDE UN TERRITORIO DIFUSO}

Naredo (2011: 55-62) resume en tres grandes bloques las consecuencias del modelo inmobiliario desarrollado durante la pasada etapa de euforia económica. Por un lado, económicas, puesto que el monocultivo inmobiliario ha generado graves endeudamientos $y$ desequilibrios. La burbuja inmobiliaria aceleró y acentuó la crisis económica en España. También ecológicas, debiendo afrontar los impactos derivados de un auténtico tsunami urbanizador que ha hecho que el suelo ocupado en la Comunidad de Madrid por usos urbano-industriales, pasase de $112 \mathrm{~m}^{2}$ por habitante en 1956 a 270 en 2005 (Naredo, 2010). Además, una ingente cantidad de suelo, anteriormente agrícola, se mantiene ahora a la expectativa para ser urbanizado en el futuro. Claro está, ha conllevado consecuencias sociales, puesto que la crisis ha traído desempleo y recortes sociales a gran escala, disparando los niveles de empobrecimiento. Los desahucios se han multiplicado en los tres últimos años, afectando a una población fuertemente endeudada que, al quedar en paro o empeorar sus condiciones laborales, no puede afrontar el pago de las deudas hipotecarias contraídas.

Pero la crisis no es solo inmobiliaria. La crisis, como plantea Fernández (2011), es una manifestación multidimensional de la inviabilidad de un modelo económico, fundamentado sobre bases ecológicas crecientemente insostenibles. 
Asimismo, el declive energético que nos espera en el siglo XXI obliga a replantearse necesariamente el futuro de las metrópolis puesto que su continuidad, tal y como lo conocemos hoy, no resulta factible.

En Madrid, como se ha explicado a lo largo del artículo, el nuevo modelo territorial se ha desplegado favoreciendo el uso masivo del automóvil privado, devorando suelo de forma insaciable. Pero a pesar de que este modelo se ha demostrado reiteradamente inviable, los responsables políticos y los grupos empresariales y sindicales continúan insistiendo, como lo hicieron en décadas pasadas, en la ideología del crecimiento, promoviendo la continuación de la política de desarrollo de grandes infraestructuras $y$ operaciones terciarias.

Sin embargo, la apuesta razonable parecería ir en un sentido muy diferente, tratando de desandar el camino y promoviendo otro tipo de estructuras territoriales:

(...) es perentorio plantear la urgencia de la desestructuración de las metrópolis mediante su transformación social y ecológica como primer paso en el camino de la consecución de un nuevo modelo territorial más disperso y autosuficiente. A través del logro de una mayor autonomía por barrios, la reducción de la necesidad de transporte motorizado, la disminución del consumo energético, el aprovechamiento $y$ transformación de la edificación actual para dar respuesta a las necesidades existentes - vivienda, empleo, centros sociales- (sin fomentar nuestra actividad constructiva exnovo), el impulso de una mayor autosuficiencia alimentaria -p.e., huertos urbanos... (Fernández y Vega, 1994: 310).

\section{BIBLIOGRAFÍA}

Abril, Guillermo. "Aquí vivo solo". El País Semanal 1790. 2011: 30-39.

Brenner, Neil y Theodore, Nik. Spaces of neoliberalism. Urban restructuring in North America and Western Europe. Oxford: Blackwell Publishing, 2002.
Capel, Horacio. Capitalismo y morfología urbana en España. Barcelona: Los Libros de la Frontera, 1983.

Colectivo Ioé. Inmigración y vivienda en España. Madrid: Observatorio Permanente de la Inmigración, 2007.

Consejería de Empleo, Mujer e Inmigración. Informe de la población extranjera empadronada en la Comunidad de Madrid. Madrid, 2011.

Díaz Orueta, Fernando. "Los procesos de descentralización demográfica en las grandes ciudades. El caso español y una aproximación a otras ciudades del Sur de Europa”. Economía y Sociedad 5. 1992: 221-233.

Díaz Orueta, Fernando. "Madrid: ¿también ciudad global?”. Primeras Jornadas de Ciencias de lo Urbano. Alicante, 1994.

Díaz Orueta, Fernando. Desequilibrios socioterritoriales en la Comunidad de Madrid en la etapa de reestructuración económica. Madrid: Universidad Complutense de Madrid, 2001.

Ecologistas en Acción. "Desertificación en España: más allá de los Tópicos”. El Ecologista 54. 2007: 18-21.

Ecologistas en Acción. "Carreteras: la crisis frena algo la locura". Madrid Ecologista 15. 2009: 9.

Fernández Durán, Ramón. "El sistema de transportes en Madrid". Primeras Jornadas sobre la Autonomía de Madrid. Madrid: Diputación Provincial de Madrid, 1981.

Fernández Durán, Ramón. La quiebra del capitalismo global: 2000-2030. Preparándonos para el comienzo del colapso de la civilización industrial. Madrid: Virus, Libros en Acción y Baladre, 2011.

Fernández Durán Ramón y Vega, Pilar. "Modernización-Globalización versus transformación ecológica y social del territorio". Ciudad y Territorio. Estudios Territoriales 100-101. 1994: 293-311.

Gavira, Carmen. "La ciudad y la no ciudad. Madrid (1567-1993)". Madrid, centro y periferia. Gavira, J. y Gavira, C. (eds.). Madrid. Biblioteca Nueva, 1999: 111-148. 
Leal, Jesús. "El boom inmobiliario madrileño: precios altos para rentas bajas". Alfoz 46 . 1987: 23-84.

Leal, Jesús. "Cambio social y desigualdad espacial en el área metropolitana de Madrid (1986-1991)". Economía y Sociedad 10. 1994: 61-81.

Leal, Jesús. "Desigualdad social, segregación $y$ mercado de vivienda en Madrid". Vivienda y segregación en las grandes ciudades europeas. Leal, J. (coord.). Madrid. Ayuntamiento de Madrid, 2007: 15-46.

Leira, Eduardo; Gago, Jesús y Solana, Ignacio. "Madrid: cuarenta años de crecimiento urbano". Ciudad y Territorio 2. 1976: 135-159.

López de Lucio, Ramón. "La tendencia hacia la dispersión/fragmentación de los territorios urbanos. Notas sobre la estructura espacial de la región urbana de Madrid". Economía y Sociedad 12. 1995: 45-58.

Lourés Seoane, María Luisa. "Patrimonio natural y territorio. La Sierra del Rincón en la Comunidad Autónoma de Madrid". Hábitat. Boletín $C F+S$ 22. 2002. En: $<$ http://habitat.aq.upm.es/boletin/n22/ amlou.html> [consultado el 9 de marzo de 2012].

Lourés Seoane, María Luisa. "Recualificación urbana $y$ desigualdad social: los barrios en crisis en Europa". Pobreza urbana. Perspectivas globales, nacionales y locales. Varios Autores. Toluca: Centro de Estudios sobre Marginación y Pobreza, 2003.

Méndez, Ricardo. "Crecimiento periférico y reorganización del modelo metropolitano en la Comunidad de Madrid". Economía y Sociedad 10. 1994: 149-173.

Naredo, José Manuel. Presión inmobiliaria y destrucción de sistemas agrarios y suelos de calidad. El ejemplo de la Comunidad de Madrid. Zaragoza: Sociedad Española de Historia Agraria-Documentos de Trabajo, DT-SEHA, 2010.

Naredo, José Manuel. "El modelo inmobiliario español y sus consecuencias”. El modelo inmobiliario español y su culminación en el caso valenciano. Naredo, J.M. y Montiel Márquez, A. (eds.). Barcelona. Icaria, 2011: 11-69.

Observatorio de las migraciones y de la convivencia intercultural de la ciudad de Madrid. Adecuación de los servicios municipales a la diversidad. Madrid y la inmigración. Madrid: Ayuntamiento de Madrid, 2005.

Observatorio Metropolitano. Madrid: ¿La suma de todos? Globalización, territorio $y$ desigualdad. Madrid: Traficantes de Sueños, 2007.

Ortí, Alfonso. "Dominación de clase y configuración social del espacio: Madrid, de capital de la oligarquía a capital del capital". Economía y Sociedad 4. 1990: 11-23.

Prada Llorente, Esther Isabel. "Concentración espacial de la propiedad de la tierra, megaproyectos inmobiliarios $y$ transformación del paisaje: caso Valdeluz". Ciudad y Territorio. Estudios Territoriales 163. 2010: 49-66.

Preteceille, Edmond. "Segregation, class and politics in large cities". Cities in Contemporary Europe. Bagnascho, A. y Le Galès, P. (eds.). Cambridge. Cambridge University Press, 2000: 74-97.

Prieto Moreno, Francisco. "Tres problemas del suburbio madrileño". Gran Madrid 2. 1948.

Roch, F. "El modelo inmobiliario español". Desigualdad social y vivienda. Díaz Orueta, F. y Lourés Seoane, M.L. (eds.). Alicante. ECU, 2004: 31-52.

Roch, F. "Madrid se desborda. A propósito de las relaciones entre lo local y lo global bajo la hegemonía inmobiliaria”. IT 75. 2006: 50-57.

Segura, Paco. "Las infraestructuras de transporte en España. Una visión crítica". Jornadas: infraestructuras de transporte, mitos y realidades. Madrid, 2011.

Fecha de ingreso: 12/03/2012

Fecha de aprobación: 14/05/2012 